\title{
The Perception of Students of UiTM, Cawangan Pulau Pinang Towards the Use of Salutations in WhatsApp Conversations
}

\author{
Noraziah Mohd Amin ${ }^{1}$, Wan Noorli Razali \\ \{noraziahm@uitm.edu.my¹,wannoorli093@uitm.edu.my²\} \\ Akademi Pengajian Bahasa, Universiti Teknologi MARA, Cawangan Pulau Pinang, \\ Permatang Pauh, Pulau Pinang, Malaysia ${ }^{1}$, Akademi Pengajian Bahasa, Universiti Teknologi MARA, \\ Cawangan Pulau Pinang, Permatang Pauh, Pulau Pinang, Malaysia ${ }^{2}$
}

\begin{abstract}
Instant messaging service has become prevalent in today's life with the ubiquitous use of mobile devices like smartphones. One of the most popular instant messaging applications is WhatsApp. Due to WhatsApp being a common application used by the majority of the students of Universiti Teknologi MARA (UiTM), Cawangan Pulau Pinang, the present study aimed to determine the perception of this university's students towards salutation or greeting use in WhatsApp conversations. The study employed a quantitative research design for its data collection. 100 respondents from the university involved in a survey conducted for this study. It was found that the majority of them were aware of their use of salutations or greetings in WhatsApp conversations as well as their preferred language for salutations on WhatsApp. The findings revealed that the students believed it is important for them to utilise full-word and formal form of salutation when communicating with their lecturers via WhatsApp.
\end{abstract}

Keywords: Salutation, Students of UiTM, Cawangan Pulau Pinang, WhatsApp

\section{Introduction}

\subsection{Background Information}

WhatsApp is a cross-platform instant messaging app for mobile devices which depends on the internet for transmission of messages and WhatsApp is the world's most popular mobile chat application with about 1.6 billion active monthly users as of 2019 [1]. University students like the ones of UiTM, Cawangan Pulau Pinang mostly have a WhatsApp account, as it is the primary medium of communication between them and their lecturers especially. As virtual communication like conversations on Whatsapp is usually lack of non-verbal cues like facial expressions and tone of voice, the message recipients have to rely solely on the written texts received for social and interpersonal interpretations between the senders and the receivers.

Fangl, Lu, Zhang, $\mathrm{Gu}$ and $\mathrm{Gu}$ [2] believe that showing linguistic politeness is a fundamental way of developing communicative skills and being socially comfortable. Besides, Fangl, Lu, Zhang, $\mathrm{Gu}$ and $\mathrm{Gu}[2]$ also claim that linguistic politeness plays a massive role in human contact and some examples of linguistic politeness are greetings, salutations, and gratitude expressions. Based on this claim, the present study intended to discover if students of UiTM, Cawangan Pulau Pinang use salutations in their WhatsApp conversations and how they usually use such linguistic components. Apart from greetings or salutations, the study also aimed at uncovering 
the if there is any employment of abbreviations or shortened words in WhatsApp conversations among the students of UiTM, Cawangan Pulau Pinang as these linguistic forms are very common in instant messaging. This is evident in the study of Salem [3] that exposed the use of abbreviations by Kuwaiti students on WhatsApp such as "Ty" for "Thank you", "I L u" for "I love you", "W 1 c" for "Welcome", "Nn" for "No need", "Np" for "No problem", "Nw" for "now" and "Bk" for "back". These are among the WhatsApp language manifestations that are claimed by Salem [3] to have negative effects on English language use such as in terms of vocabulary and spelling. Despite this, people especially the youngsters continue to use abbreviations on instant messaging applications. Thus, the present study was conducted to investigate salutations, abbreviations as well as preferred language for salutations in WhatsApp conversations among a university's students who could represent the other youngsters.

\subsection{Problem Statement}

Clement [1] claims that WhatsApp is the world's most popular mobile messaging application with roughly 1.6 billion monthly active users as of 2019, outstripping Facebook Messenger at 1.3 billion and WeChat at 1.1 billion users. It is also the third most popular networking site globally, after Facebook and YouTube. This is clear that WhatsApp is used widely in many countries including Malaysia. Due to its popularity, the use of WhatsApp is worth studying especially in terms of linguistic elements in teenage users' texts in their conversations on WhatsApp. As claimed by Salem [3], online messaging apps such as WhatsApp have a negative effect on the use of English. It is also claimed by Salem [3] that Kuwaiti teenagers particularly and young people generally use certain abbreviations or shortcut codes to communicate their thoughts to the extent that this spoils their both English grammar and spelling. English learners using modern communication technologies (like WhatsApp) in particular text messaging are making various errors ranging from inaccurate spelling to nongrammatical sentence structure [3]. As this is true for Kuwaiti youngers, it is unclear if university students like the ones of UiTM, Cawangan Pulau Pinang also practice the same thing, and thus this prompted the present study to be conducted in order to discover if these students use any abbreviations in their WhatsApp conversations and how they use the shortened words.

Apart from abbreviations, another issue that is important to be examined is the use of salutations or greetings on WhatsApp because there is some evidence that university students do not use these politeness markers in their virtual communication. For example, the conclusion made by Harizah and Suhaila [4] based on the results obtained in their study is that the majority of the university students did not succeed at employing suitable politeness strategies that could reduce face-threatening acts between themselves and their lecturers. This shows that the improper manner and having lack of professional attitude in conversations between the youngsters and those older than them is a worrisome issue. Besides, the analysis of 278 SMS text messages in a study conducted by Rettie [5] exposed that most of the messages were not formal with minimal structure where only $23 \%$ consisted of opening or closing phrases (e.g: $19 \%$ salutations, $12 \%$ sign-off expressions. The lack of salutations used in instant messaging texts among youngers is probably true for these researchers' study participants, but it is possibly not the same case for students of UiTM, Cawangan Pulau Pinang and thus a study has to be conducted in order to discover this.

\subsection{Research Objectives}

This study was conducted to investigate the perceptions of students of UiTM, Cawangan Pulau Pinang towards salutations or greetings in WhatsApp conversations. There are three objectives of this study of which are: 
1. To investigate if students of UiTM, Cawangan Pulau Pinang prefer full-word or short-form salutations in their WhatsApp conversations.

2. To investigate if students of UiTM, Cawangan Pulau Pinang prefer formal or informal salutations in their WhatsApp conversations.

3. To investigate if students of UiTM, Cawangan Pulau Pinang prefer English or Malay salutations in their WhatsApp conversations.

\subsection{Significance of the Study}

It is hoped that this study will serve as a source of additional knowledge regarding the topic of the use of salutations on WhatsApp and also spread awareness about the importance of paying attention to linguistics cues for social and interpersonal purposes. Besides, through this study, it is expected that it could be an inspiration for many other researchers to conduct more research on the same issue as more evidence can be obtained for a more definitive generalization.

\section{Literature Review}

\subsection{The Features and Uses of WhatsApp as a Medium of Communication}

Clement [1] believes that WhatsApp, particularly for global or group messaging, is a convenient option to carrier-billed text messaging via SMS. The mobile messaging app allows users to exchange text, picture, video, voice text, and video calling as well. In addition, every day, the service manages billions of pictures and text messages. According to Robinson et. al [6] ,WhatsApp is a cross-platform mobile instant messaging (MIM) that is free to download and it allows people to exchange texts without needing to pay for their text messages. Also, WhatsApp immediacy seems to offer advantages over embedded social media sites like the discussion boards [6]. According to Ersöz [7], one of WhatsApp's most valuable features is that it permits mobile users to send instant messages in real time, at no expense to individuals or groups of friends. Ersöz [7] also believes that WhatsApp's rapid and widespread growth helps its users to communicate with one another despite the fact of the distance.

\subsection{Abbreviation Use in WhatsApp Conversations}

A research conducted by Farhang-Ju [8] on WhatsApp conversations containing graduate students' requests to their instructors revealed that the students had a tendency to use short messages and more abbreviations. Farhang-Ju [8] also claims that the use of abbreviated expressions such as "plz", "tnx", "thanx", and "u" is possibly due to the restricted amount of time and phone keyboards' small size. Indrajith and Varghese [9] claim that people have different abbreviations for similar messages. Based on their study, it is concluded that salutation, "Good Morning" can be expressed in various ways on WhatsApp as it can be articulated as "gdmg", "gudmng" or simply "gm". It is also the same case with the salutation, "Good Night" where the teenagers tend to write "gdnt", "gudnite" or just "gn". However, the most frequent abbreviations used were found to be "hru?" and "wru?" [9]. According to Shahid [10], during the analysis of her study, a number of abbreviations were observed on WhatsApp conversations involving 25 students and 25 professionals such as "asap" ("as soon as possible"), "tc" ("take care") and "lol" ("lots of laughter"). 


\subsection{The Usage of Formal and Informal Greetings or Salutations on Instant Messengers}

The study conducted by Harizah and Suhaila [4] analyzed the practice of social greetings in computer-mediated communication, concentrating on 50 Short Message Service (SMS) messages from students to lecturers in a private university in Malaysia. It was discovered in the study that most of the students did not use the more common salutations such as "Good Morning" and "Good Afternoon" (14\%), but instead used a more informal greeting such as "Miss" (20\%) instead of the traditional style anticipated. Other informal greetings that students used as indicated in the study include "Hi" and its variants (8\%) and also "Hello" (12\%). To summarize, a majority of the students failed to use proper politeness approaches in their conversations with their lecturers that could minimize face-threatening acts between the students and their lecturers [4]. It was revealed in a study performed by Marzuki and Walter [11] that the Malay L1 users were discovered to have employed formal letter-type salutations and professional titles, frequently in their first language text messages and sometimes in their second language one. Matli [12] conducted a study on undergraduates' language use in a messaging service application, WhatsApp conversations with their fellow peers and lecturers by analyzing their textual interactions. It was found that the students used a slang, "Ta" which is a word commonly used by people in the ghetto as compared to "Hello" or "Hi". The study of Pérez-Sabater [13] revealed that males generally are more straightforward, while females usually use greetings to introduce their texts. It was also disclosed that men-only chat represents the briskness of masculine interactions, in the sense that there are generally no salutations or farewells and there are a lot of imperative forms, even though in this case, there exist some kind of greeting through a rather colloquial word such as "Yeeee," the equivalent of "Wassuup" in English.

\section{Methodology}

\subsection{Research Design}

The present study employed a quantitative research design using a questionnaire survey to investigate the perception of students of UiTM, Cawangan Pulau Pinang towards salutations or greetings in WhatsApp conversations. The research did not involve any observations or lab experiment and it is basically descriptive in nature.

\subsection{Respondent}

The respondents who participated in the research and contributed to the study's data were from UiTM, Cawangan Pulau Pinang, who were 100 degree students aged between 20-23 years old. The number of the respondents qualified for the present research was decided after eliminating the questionnaires returned with missing data. Their demographic details, such as their gender, age, or fields of studies, were not investigated or measured in this study. Thus, such data was not utilized for the discussions of the research questions posed, but it is presented as supplementary information.

\subsection{Sampling Method Research Design}

In this study, convenience sampling was performed. Convenience sampling is a category of non-probability or non-random sampling where people of the target population that meet certain practical conditions, such as easy accessibility, geographical proximity, availability at a given time, or the willingness to participate are chosen for achieving the objective of the study 
[14]. Thus, the researchers decided to ask the available students at the time of questionnaire distribution. This helped the researchers to get the respondents quickly.

\subsection{Instrument}

A questionnaire was created to be the research instrument for collecting data from the respondents. This method was more effective than interviewing them face-to-face as interviews can be time-consuming. The questionnaire was not adapted by any measurement scales of the previous quantitative studies as most studies regarding the use of salutations in instant messaging used content analysis. Thus, the present study's questionnaire was adapted from the studies of Tagliamonte and Denis [15] and Harizah and Suhaila [4]. The questionnaire was created using Google form and it contained 20 questions. The items in the questionnaire were measured in terms of the respondents' levels of agreement or disagreement with the 20 statements by using a 5-point Likert scale. The response options are: Strongly disagree= 1; Disagree $=2 ;$ Undecided $=3 ;$ Agree $=4$ and Strongly agree $=5$.

\subsection{Data Collection Method}

The data was collected using a Google form link sent to the students' WhatsApp groups and their participation was voluntary. A brief introduction and instructions were given to the respondents in the message containing the Google form link sent to the respondents and they were given a number to contact should they have any doubts pertaining to the questionnaire. A duration of two weeks was given to the students to complete the questionnaire.

\subsection{Data Analysis Method}

The data obtained was analyzed using Statistical Package for the Social Sciences (SPSS) version 18. The data was computed into this software and generated mainly in terms of mean and standard deviation values as well as percentages.

\section{Findings}

\subsection{Reliability Test Result}

Table 1. Cronbach's Alpha Reliability Coefficient for the Instrument

\begin{tabular}{ccc}
\hline $\begin{array}{c}\text { Cronbach's } \\
\text { Alpha }\end{array}$ & $\begin{array}{c}\text { Cronbach's Alpha Based on Number of } \\
\text { Standardized Items }\end{array}$ & items \\
\hline 0.927 & 0.928 & 20
\end{tabular}

An analysis was carried out to test the items' reliability. 0.927 was the Cronbach's alpha value generated from the test. This value indicated acceptable values that showed the items in the questionnaire were reliable as well reasonable to be utilized for the present research.

4.2 Research Objective 1: To investigate if students of UiTM, Cawangan Pulau Pinang prefer full-word or short-form salutations in their WhatsApp conversations. 
Table 2. Results of Research Objective 1

No. Items

\section{Full-word or Short-form Salutation in WhatsApp Conversations}

1 I prefer short-form salutations when chatting with my friends on WhatsApp such as "Salam" rather than full-word salutations such as "Assalamualaikum."

2 I think I should use full-word salutations to greet my friends on WhatsApp rather than short-form salutations because fullword ones are more convenient to start a conversation.

3 I think I should use short-form salutations to greet my friends because it seems friendlier to do so in WhatsApp conversations.

4 I tend to use short-form salutations with people that I already know or close to rather than full word salutations because the short-form ones make me feel more comfortable.

5 I prefer to use full-word salutations when I contact my lecturers rather than short-form salutation on WhatsApp as this can show my proper manners.

6 I prefer to use full-word salutations because they can show that I am more committed to the conversations on WhatsApp as compared to the short-form ones.

7 I prefer to use short-form salutations with online sellers that I 3.01 contact on WhatsApp.

8 I prefer to use full-word salutations because they are more appropriate to start a discussion on a WhatsApp group with many different people rather than short-form salutations.

Mean Std. Response

Dev SD D U A SA $\% \% \% \% \%$

$\begin{array}{lllllll}3.06 & 1.377 & 15 & 26 & 18 & 20 & 21\end{array}$

$\begin{array}{lllllll}3.41 & 1.281 & 8 & 19 & 24 & 22 & 27\end{array}$

$\begin{array}{lllllll}3.27 & 1.207 & 8 & 20 & 28 & 25 & 19\end{array}$

$\begin{array}{lllllll}3.74 & 1.222 & 6 & 12 & 19 & 28 & 35\end{array}$

$\begin{array}{lllllll}4.05 & 1.329 & 7 & 12 & 8 & 15 & 58\end{array}$

$\begin{array}{lllllll}3.46 & 1.260 & 8 & 17 & 22 & 27 & 26\end{array}$

$1.299 \quad 14 \quad 262123 \quad 16$

To evaluate the first objective, responses provided by the participants to items 1-8 were analyzed. It was discovered that $41 \%$ of the respondents (Item1: $\mathrm{M}=3.06, \mathrm{SD}=1.377$ ) preferred short-form salutations when chatting with their friends through WhatsApp such as "Salam" rather than full-word salutations such like "Assalamualaikum." Most respondents (49\%) believed they should use full-word salutations with their friends due to their convenience (Item 2: $\mathrm{M}=3.41, \mathrm{SD}=1.281$ ). $44 \%$ of them believed it is friendlier to use short-form salutations (Item 3: $\mathrm{M}=3.27, \mathrm{SD}=1.207) .63 \%(28 \%+35 \%)$ of them agreed that they were more comfortable using short-form salutations especially with those known to them or closely related to them (Item 4: $\mathrm{M}=3.74, \mathrm{SD}=1.222$ ). $73 \%$ of the students also preferred the use of full-word salutations when communicating with their lecturers (Item $5: \mathrm{M}=4.05, \mathrm{SD}=1.329$ ) as this could present their proper manners. A majority of the respondents (53\%) favored full-word than short-form salutations (Item 6: $\mathrm{M}=3.46, \mathrm{SD}=1.260$ ) as they believed such words reflected their commitment to the conversations. A majority of the respondents, $26 \%$ disagreed with the use of short-form salutations when communicating with online sellers on WhatsApp (Item 7: $\mathrm{M}=3.01$, $\mathrm{SD}=1.299$ ). $55 \%$ of them (Item $8: \mathrm{M}=3.48, \mathrm{SD}=1.261$ ) agreed that it was more appropriate to use full-word salutations when starting a discussion. 
4.4 Research Objective 2: To investigate if students of UiTM, Cawangan Pulau Pinang prefer formal or informal salutations in their WhatsApp conversations.

Table 3. Results of Research Objective 2

\begin{tabular}{|c|c|c|c|c|c|c|}
\hline No. & $\begin{array}{c}\text { Formal or Informal Salutations in } \\
\text { Whatsapp Conversations }\end{array}$ & Mean & $\begin{array}{l}\text { Std. } \\
\text { Dev }\end{array}$ & & $\begin{array}{l}\text { Respons } \\
\text { Option } \\
\text { D U A } \\
\% \% \%\end{array}$ & $\begin{array}{c}\text { SA } \\
\%\end{array}$ \\
\hline 9 & $\begin{array}{l}\text { I like to be called "bro" or "sis" (informal salutations) rather } \\
\text { than "Mr", "Ms" or "Madam" (formal salutations) in } \\
\text { WhatsApp conversations. }\end{array}$ & 3.41 & 1.326 & 11 & 142424 & 27 \\
\hline 10 & $\begin{array}{l}\text { I think formal salutations should be used with someone that I'm } \\
\text { not familiar with in WhatsApp conversations. }\end{array}$ & 3.71 & 1.320 & 9 & 131626 & 36 \\
\hline 11 & $\begin{array}{l}\text { I tend to use formal salutations mostly because they more } \\
\text { polite in WhatsApp conversations rather than informal } \\
\text { salutations. }\end{array}$ & 3.16 & 1.150 & 10 & 183328 & 11 \\
\hline 12 & $\begin{array}{l}\text { When chatting with a lecturer or someone that is more superior } \\
\text { than me, I prefer to use formal salutations rather than informal } \\
\text { salutations to show my good manners. }\end{array}$ & 4.02 & 1.365 & 10 & $\begin{array}{lll}10 & 5 & 21\end{array}$ & 54 \\
\hline 13 & $\begin{array}{l}\text { I think I should use informal salutations with the closest } \\
\text { people, such as family members or good friends, because it } \\
\text { is more comfortable for me to use such words on WhatsApp. }\end{array}$ & 3.83 & 1.280 & 8 & 101132 & 39 \\
\hline 14 & $\begin{array}{l}\text { I would like to be greeted with formal salutations from people } \\
\text { that I do not know well on WhatsApp. }\end{array}$ & 3.69 & 1.207 & 7 & 102329 & 31 \\
\hline $15 \mathrm{I}$ & $\begin{array}{l}\text { I would like to be greeted with informal salutations by my } \\
\text { friends on WhatsApp. }\end{array}$ & 3.86 & 1.202 & 8 & $\begin{array}{lll}5 & 19 & 31\end{array}$ & 37 \\
\hline
\end{tabular}

In achieving research objective 2, Items 9-15 were analyzed. It was discovered that 51\% of the respondents preferred to be addressed informally on WhatsApp (Item 9: $\mathrm{M}=3.41$, $\mathrm{SD}=1.526) .62 \%$ of them believed that formal salutations were used to greet those who were unfamiliar to them (Item 10: $\mathrm{M}=3.71, \mathrm{SD}=1.320) .39 \%(28 \%+11 \%)$ of them believed that it was more polite to use formal salutations on WhatsApp (Item 11: $\mathrm{M}=3.16, \mathrm{SD}=1.150$ ). To display good manners, $75 \%(21 \%+54 \%)$ of the respondents believed that formal salutations were required when communicating with their lecturers or someone superior on WhatsApp (Item 12: $\mathrm{M}=4.02, \mathrm{SD}=1.365$ ). Nevertheless, they mostly favored informal salutations when talking to family members or close friends (Item 13: M=3.83, SD=1.280). When being greeted by people not close to the respondents, the respondents in majority preferred to be greeted formally (Item 14: $\mathrm{M}=3.69, \mathrm{SD}=1.207$ ). However, informal greetings from their friends on WhatsApp were more favored by the respondents (Item 15: $\mathrm{M}=3.86, \mathrm{SD}=1.202$ ).

4.5 Research Objective 3: To investigate if students of UiTM, Cawangan Pulau Pinang prefer English or Malay salutations in their WhatsApp conversations. 
Table 4. Result of Research Objective 3

\begin{tabular}{|c|c|c|c|c|c|c|}
\hline No. & $\begin{array}{c}\text { English or Malay salutations in WhatsApp } \\
\text { Conversations }\end{array}$ & Mean & $\begin{array}{l}\text { Std. } \\
\text { Dev }\end{array}$ & $\begin{array}{c}\text { SD } \\
\%\end{array}$ & 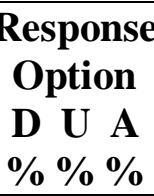 & $\begin{array}{c}\text { SA } \\
\%\end{array}$ \\
\hline 16 & $\begin{array}{l}\text { I prefer to use English salutations such as "Hello" or "Hi" to } \\
\text { start a conversation rather than Malay salutations such as } \\
\text { "Salam" or "Selamat Sejahtera" om WhatsApp. }\end{array}$ & 3.04 & 1.365 & 16 & 232320 & 18 \\
\hline 17 & $\begin{array}{l}\text { I think we should use Malay salutations more often on } \\
\text { WhatsApp as Malay is Malaysia's official language. }\end{array}$ & 3.61 & 1.136 & 4 & 142927 & 26 \\
\hline 18 & $\begin{array}{l}\text { I think Malay salutations are more preferable for me to use on } \\
\text { WhatsApp with most people as they are more universal in } \\
\text { Malaysia as they represent Malaysians' national language. }\end{array}$ & 3.71 & 1.163 & 6 & 131442 & 25 \\
\hline 19 & $\begin{array}{l}\text { English salutations are more preferable for me to use on } \\
\text { WhatsApp because they can show that I have good English. }\end{array}$ & 3.12 & 1.168 & 12 & 173328 & 10 \\
\hline 20 & $\begin{array}{l}\text { I agree that the use of a certain language for salutations on } \\
\text { WhatsApp can reflect someone's cultural politeness. }\end{array}$ & 3.88 & 1.168 & 5 & 111434 & 36 \\
\hline
\end{tabular}

In terms of completing research objective 3, items 16-20 were analyzed. 39\% $(16 \%+23 \%)$ of the respondents disagreed with using English salutations when communicating on WhatsApp (Item 16: $\mathrm{M}=3.04, \mathrm{SD}=1.365)$. A majority of the respondents, 53\% $(27 \%+26 \%)$ agreed that they favored Malay more often compared to English salutations (Item 17: M=3.61, SD=1.136) and a higher percentage of $67 \%(42 \%+25 \%)$ believed that Malay salutations were more preferable as Malay is more common in this country (Item 18: M=3.71, SD=1.163). When responding to the statement, "English salutations are more preferable for me to use on WhatsApp because they can show that I have good English", 28\% of the respondents agreed with this (Item 19: $\mathrm{M}=3.12, \mathrm{SD}=1.168)$. A huge percentage, $70 \%(34 \%+36 \%)$ of the respondents had the opinion that the language preference for salutations used on WhatsApp signaled the users' cultural politeness (Item 20: $\mathrm{M}=3.88, \mathrm{SD}=1.168$ ).

\section{Discussion and Conclusion}

Based on the findings, it is clear that short-form salutations are preferred by the respondents when conversing with those they are familiar with on WhatsApp due to the fact that it is friendlier to do so. Full-word salutations on the other hand, are preferred by the respondents due to their convenience of use as well as their polite and appropriate nature especially when dealing with their lecturers or someone unfamiliar to them. Such words are also deemed more appropriate to be used when initiating a discussion on WhatsApp. With regard to formal and informal salutations, informal ones are more favored by the respondents when dealing with those whom they know and are close to. In contrast, formal salutations are viewed as a polite way of addressing someone superior or unfamiliar to them and this includes their lecturers. In terms of language preference when giving salutations, the students have almost similar preference of for both Malay and English salutations. Malay is seen as a more universal language in the country compared to English by the respondents as it stands by its status as the 
national language and the medium of interaction among those whose first language is Malay. English salutations however are used when the students wish to be seen as proficient language users.

Here, it can be concluded that the respondents realize that full-word salutations signal their politeness and are needed to be used when interacting with their lecturers on WhatsApp despite the claim by Farhang-Ju [8] that most students have the tendency to use abbreviations and short messages with their instructors. They also acknowledge the need to address a person formally to display politeness especially when communicating with those superior to them. However, realization and acknowledgement may not be sufficient to ensure that proper salutations are used when students communicate with their lecturers on WhatsApp. Constant reminder and advice need to be given to students to instill politeness in them and to inculcate respectful environment on WhatsApp. In conclusion, the current study has paved a direction for future research in exploring the practice of politeness in greetings and use of salutations among university students.

\section{Acknowledgements}

Acknowledgements. The researchers would like to thank UiTM, Cawangan Pulau Pinang for its support to academics in conducting research concerning their related field and financial opportunities in disseminating research findings and sharing them either locally or internationally. 


\section{References}

[1] J. Clement, "WhatsApp - Statistics \& Facts," Statista, 2019. [Online]. Available: https://www.statista.com/topics/2018/whatsapp/.

[2] Y. Fangl, T. Lu, P. Zhang, H. Gu, and N. Gu, "Exploring the Effect of Politeness on User Contribution in Q\&A sites: A Case Study of Stack Overflow," in 2018 IEEE 22nd International Conference on Computer Supported Cooperative Work in Design ((CSCWD)), 2018, pp. 713-718.

[3] A. A. M. S. Salem, "The impact of Technology ( BBM and WhatsApp Applications ) on English Linguistics in Kuwait," Int. J. Appl. Linguist. English Lit., vol. 2, no. 4, 2013.

[4] H. Faiz and N. S. Suhaila, "Use of Greetings in SMS Messages from Students to Lecturers at a Malaysian University," Int. J. Soc. Sci. Humanit., vol. 3, no. 2, pp. 125-128, 2013.

[5] R. Rettie, "SMS: Exploiting the interactional characteristics of near-synchrony," Information, Commun. Soc., vol. 12, no. 8, pp. 1131-1148, Dec. 2009.

[6] L. Robinson et al., "Evaluation of Whatsapp for Promoting Social Presence in a First Year Undergraduate Radiography Problem-Based Learning Group," J. Med. Imaging Radiat. Sci., vol. 46, no. 3, pp. 280-286, 2015.

[7] S. Ersöz, "Understanding Whatsapp Parent Groups' Dynamics: Group Communication and Information Sharing," Manas Sos. Araştırmalar Dergisi, 8(Ek Sayı 1), vol. 8, no. 1, pp. 1167-1183, 2019.

[8] M. Farhang-ju, "A Window to L2 Learners ' Requests to Faculty in Instant Text-Based Communication," CALL-EJ, vol. 21, no. 1, pp. 29-41, 2020.

[9] T. Varghese and I. J. Indrajith, "Language to 'Lang': WhatsApp Imprints on Teenagers," Acme Int. J. Multidiscip. Res., vol. 6, no. 1, Jan. 2018.

[10] S. Shahid, "Content Analysis of Whatsapp Conversations: An Analytical Study to Evaluate the Effectiveness of Whatsapp Application in Karachi," Int. J. Media, Journal. Mass Commun., vol. 4, no. 1, pp. 14-26, 2018.

[11] E. Marzuki and C. Walter, "English and Malay Text Messages and What They Say about Texts and Cultures," Open J. Mod. Linguist., vol. 3, no. 4, pp. 295-304, Jan. 2013.

[12] W. Matli, "How Undergraduate Students "Chat Language'in Whatsapp," in 2019 Open Innovations (OI), 2019, pp. 401-407.

[13] C. Pérez-Sabater, "Emoticons in relational writing practices on WhatsApp: Some reflections on gender," in Analyzing Digital Discourse: New Insights and Future Directions, P. Bou-Franch and P. G.C. Blitvich, Eds. Cham.Switzerland: Palgrave Macmillan., 2017.

[14] I. Etikan, S. A. Musa, and R. S. Alkassim, "Comparison of Convenience Sampling and Purposive Sampling,” Am. J. Theor. Appl. Stat., vol. 5, no. 1, pp. 1-4, 2016.

[15] S. A. Tagliamonte and D. Denis, "Linguistic ruin? Lol! Instant messaging and teen language," Am. Speech, vol. 83, no. 1, pp. 3-34, Feb. 2008. 